\title{
Cationic nanocelluloses in dewatering of municipal activated sludge
}

Terhi Suopajärvi*, Juho Antti Sirviö, Henrikki Liimatainen

Fiber and Particle Engineering Unit, P.O. Box 4300, FI-90014 University of Oulu, Finland.

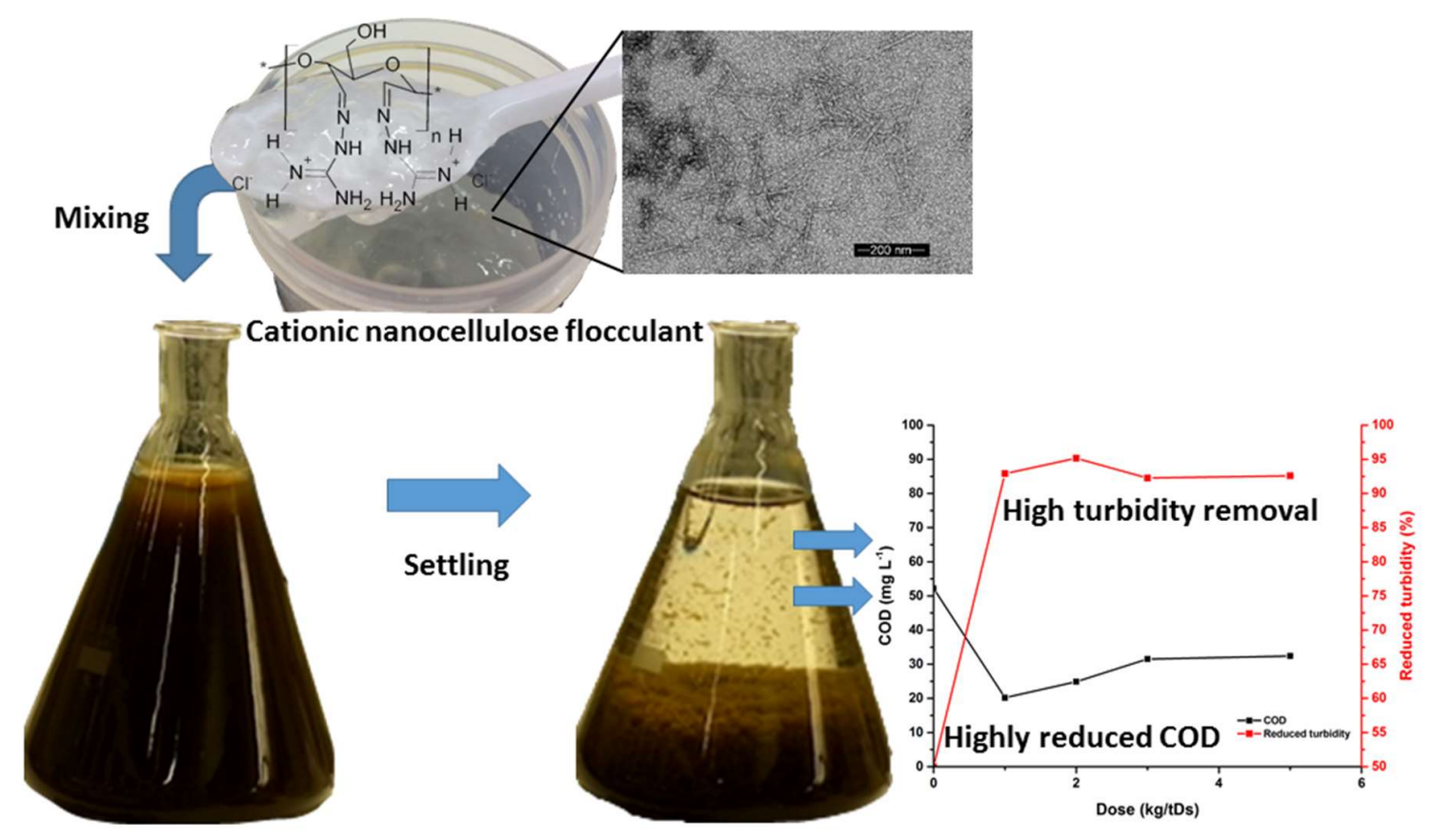

Municipal activated sludge

\begin{abstract}
This study used cationic nanocelluloses (CNFC I and II) produced by nanofibrillizing periodate oxidized and aminoguanidine hydrochloride reacted wood cellulose as flocculation agents for municipal activated sludge. For both CNFC I and II, the diameters ranged from about 2-8 nm. Lengths ranged from hundreds of nanometers for CNFC I and about 50-100 nm for CNFC II. The charge densities for CNFC I and II were 1.07 and 1.70 meq $\mathrm{g}^{-1}$, respectively. The study examined the flocculation performance of the two CNFCs in the conditioning treatment of municipal activated sludge and compared the results with the performance of both a commercial coagulant and polyelectrolyte (polyacrylamide).
\end{abstract}

*Corresponding author. Tel. +358294 482415. e-mail address: terhi.suopajarvi@oulu.fi 
Results showed that both CNFC I and II were able to flocculate activated sludge efficiently at effective doses similar to those of the commercial cationic polymer and at doses lower than the reference coagulant. Their efficiency in reducing turbidity was nearly as good as that of the synthetic reference polymer, and their COD was even better than that of the synthetic reference polymer. The performance of CNFC II was slightly better than that of CNFC I. In centrifugation analyses, the use of both CNFCs resulted in dense sludge cakes with moderate swelling and good colloidal-removal efficiency.

Keywords: Activated sludge; Cationic nanocellulose; Cellulose nanofibril; Centrifugal analysis; Flocculation 


\section{Introduction}

The activated-sludge process is highly efficient for removing organic loads from wastewater and is the most widely used biological treatment in wastewater purification. About 71,000 municipal wastewater treatment plants (WWTPs) operating in the area of the EU, which includes Iceland, Norway, and Switzerland [1], produced approximately 10 million tons (dry matter) of sewage sludge annually from 2003-2006, and that amount has been increasing continually $[2,3]$. This activated sludge commonly contains more than $90 \%$ water and exhibits poor dewaterability that is related to the presence of extracellular polymeric substances (EPS), which possess negative surface charges and hydrophilic structures $[4,5]$. Often, sludge dewatering must be enhanced by chemical conditioning before mechanical water removal. Conditioning increases particle sizes by combining small, colloidal particles into larger, cohesive aggregates. This chemical conditioning is done using inorganic, multivalent cationic coagulants such as aluminum (Al) or iron (Fe) salts or with synthetic polyelectrolytes such as synthetic polyacrylamides (PAM) [6-11]. However, PAM and its derivatives pose a number of environmental problems, as the intermediate products of their degradation are hazardous and their monomers are highly toxic. In addition, these polymers are derived from oil-based, non-renewable raw materials $[12,13]$. Furthermore, the use of inorganic salts increases both sludge volume and the ionic load of the sludge and the treated water [14]. Consequently, there is a need for sustainable, natural, bio-based alternatives for conditioning wastewater sludge.

Biodegradability is one of the most important environmental aspects of water chemicals, as it determines their long-term ecological effects [15]. In view of the increased demand for sustainable water-treatment technologies, natural polymers have been widely investigated as a means of replacing synthetic and inorganic water chemicals [16]. Natural polymers consist mainly of polysaccharides and their derivatives, and they have been studied widely 
in various water-chemical applications [17]. Of all the natural polysaccharides, cellulose is the most abundant, and it could be a primary chemical resource in the future $[16,18]$. Therefore, the modification and use of cellulose as a water chemical in wastewater treatments is attractive. Previously, we studied various functionalized nanocelluloses as water chemicals in flocculation of model kaolin waters [19-22], real wastewaters [19,2325], and in metal adsorption [23,26,27]. The results have been promising and indicate that functionalized nanocelluloses are potential future water chemicals and may also be used to condition wastewater sludge. In particular, cationic nanocelluloses could have potential for this purpose, since sludge consists mainly of anionic solids.

The present study aimed to produce cationic cellulose nanofibrils and measure their performance in conditioning municipal activated sludge. Two cationic nanocellulose flocculants (CNFC I and II) were produced by nanofibrillizing periodate oxidized and aminoguanidine-reacted wood celluloses using a microfluidizer. The conditioning performance of both CNFCs was examined by flocculating municipal activated sludge. The results were compared with the performance of a commercial coagulant and a synthetic PAM flocculant.

\section{Materials and methods}

\subsection{Raw materials and chemicals}

Dry sheets of bleached birch (Betula pendula) chemical kraft pulp was used as the cellulose raw material. Pulp was disintegrated in deionized water before the syntheses of CNFCs. The characteristics of the pulp were as presented elsewhere [24].

All chemicals used in the synthesis and characterization of the nanocellulose materials were p.a. grade and were obtained from Sigma-Aldrich (Germany). They were used without any further purification. The chemicals used to prepare the buffers for charge-density measurement by polyelectrolyte titration were $0.1 / 1 \mathrm{M} \mathrm{NaOH}$ and $\mathrm{HCl}$ (Merck, Germany), 
$\mathrm{NaH}_{2} \mathrm{PO}_{4}$ (Sigma-Aldrich, Germany), $\mathrm{NaCl}$ and $\mathrm{CH}_{3} \mathrm{COOH}$ (Merck, Germany),

$\mathrm{NaCH}_{3} \mathrm{COO}$ (Oy FF Chemicals, Finland), $\mathrm{NaH}_{2} \mathrm{PO}_{4}$ (Fluka, Germany), $\mathrm{NaHCO}_{3}$ (Merck, USA), $\mathrm{Na}_{2} \mathrm{CO}_{3}$ (J. T. Baker, USA), and $\mathrm{NaNO}_{2}$ (Sigma-Aldrich, Germany). All were p.a. grade, and all were used as received. Deionized water was used throughout the work.

PIX-105 (ferric sulphate, $\mathrm{Fe}_{2}(\mathrm{SO} 4)_{3}$ ) and Fennopol K5060 (cationic polyacrylamide) were obtained from Kemira (Finland), and were used as an inorganic coagulant agent and a reference polyelectrolyte, respectively.

Samples of municipal activated sludge were collected from the aeration tank of a local municipal WWTP from Oulu, Finland. Table 1 shows the main characteristics of the samples.

Table 1. Characteristics of the activated sludge samples from the municipal WWTP

\begin{tabular}{lcccc}
\hline Sample & $\mathbf{p H}$ & $\begin{array}{c}\text { Conductivity } \\
{[\boldsymbol{\mu S} / \mathbf{c m}]}\end{array}$ & TSS [g/L] & TS [g/L] \\
\hline Activated sludge I & 6.80 & 644 & 4.32 & 4.74 \\
Activated sludge II & 6.68 & 777 & 4.50 & 5.12 \\
\hline
\end{tabular}

TTS $=$ total suspended solids, $\mathrm{TS}=$ total solids

\subsection{Fabrication of CNFC flocculants}

Figure 1 shows the functionalization of the cellulose using two-step reaction paths based on regioselective oxidation [28]. In the first reaction step, the vicinal hydroxyl groups at positions 2 and 3 in the cellulose were oxidized to aldehyde groups using sodium metaperiodate to produce dialdehyde cellulose (DAC). Two separate DAC samples were prepared with differing aldehyde contents: DAC I had an aldehyde content of $1.68 \mathrm{mmol} \mathrm{g}$ 1, and DAC II had an aldehyde content of $2.84 \mathrm{mmol} \mathrm{g}^{-1}$ [28]. To synthesize DAC I, $6 \mathrm{~g}$ of cellulose pulp was mixed with $4.92 \mathrm{~g}$ of sodium metaperiodate in aqueous solution for 3 hours at $55^{\circ} \mathrm{C}$. DAC II was produced in the same way as DAC 1, except the reaction 
temperature was set at $75^{\circ} \mathrm{C}$. Then, cationic celluloses (CDAC I and II) were synthetized from the DAC samples using aminoguanidine hydrochloride, as described previously by Sirviö et al. (2014) [29]. To synthesize CDAC I, $7.44 \mathrm{~g}$ of aminoguanidine hydrochloride was diluted in $200 \mathrm{ml}$ of deionized water, $\mathrm{pH}$ was adjusted to 4.5 with $0.1 \mathrm{M}$ of $\mathrm{HCl}$ solution, $4 \mathrm{~g}$ of DAC I was added, and the solution was mixed at room temperature for 72 h. CDAC II was synthesized the same way except the amount of aminoguanidine hydrochloride used was $12.56 \mathrm{~g}$. Both products were purified by filtration and washing with deionized water. The cationized celluloses were Nanofibrillated into cationic nanocelluloses, CNFC I and CNFC II, using the microfluidizer M-110EH-30 (Microfluidics, USA). The CDAC I sample at the consistency of $1 \%$ was passed once through $200-\mu \mathrm{m}$ and $100-\mu \mathrm{m}$ chambers and then once $200-\mu \mathrm{m}$ and $87-\mu \mathrm{m}$ chambers. The CDAC II sample at the consistency of $0.5 \%$ was passed once through $200-\mu \mathrm{m}$ and $87-\mu \mathrm{m}$ chambers using 2000 bar pressure.



(Cellulose)

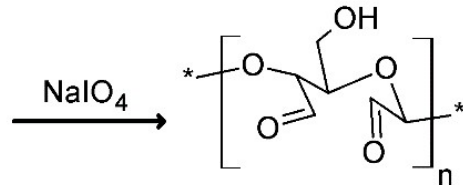

(DAC)

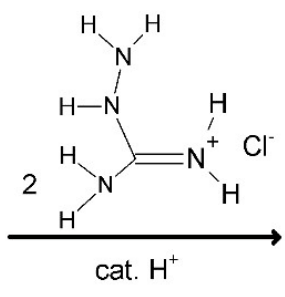

(CNFC) $\mathrm{Cl}^{-}$

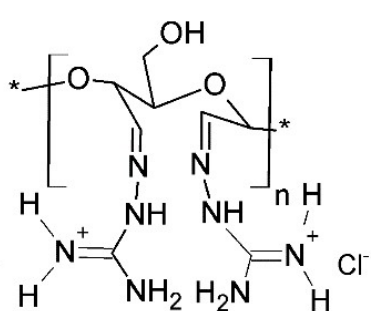

Figure 1. Periodate oxidation of cellulose and synthesis of cationic cellulose using aminoguanidine.

\subsection{Characterization of CNFCs}

\section{Optical transmittance}

Transmittance of the prepared CNFC suspensions was measured with a Hach Lange DR 2800 spectrophotometer (USA) at a wavelength range of from $340-800 \mathrm{~nm}$ at a consistency of $0.1 \%$. 


\section{Charge density}

The polyelectrolyte titrations were performed at a solids content of $0.1 \%$ mixed with the appropriate buffer using a Mütek PCD 03 particle-charge detector (USA). The CNFCs were titrated with 1 meq dm ${ }^{-3}$ of anionic PES-Na (sodium polyethenesulphonate) while the sign of the sample charge was monitored.

\section{Transmission electron microscopy}

The visualization of CNFCs was performed with a Tecnai G2 Spirit transmission electron microscope (TEM) (FEI Europe; Eindhoven, The Netherlands). A droplet of the dilute sample was dosed on top of a carbon-coated copper grid treated with polylysine, and the excess amount of the sample was removed from the grid by touching the droplet with a corner of a filter paper. Negative staining of the samples was performed by placing a droplet of uranyl acetate $(2 \% \mathrm{w} / \mathrm{v})$ on top of each specimen. The excess amount of the uranyl acetate was removed with filter paper as described above. Grids were dried at room temperature and analyzed at $100 \mathrm{kV}$ under standard conditions.

\section{Dewatering experiments}

Next, $1000 \mathrm{ml}$ samples of activated sludge were treated with CNFC, ferric coagulant, or cationic flocculants. To keep the content of solids constant, the proper amount of water was added to the sludge samples with low doses of flocculation aid. After the flocculation aid was added, the sludge samples were stirred with a magnetic stirring bar at $200 \mathrm{rpm}$ for 2 min at room temperature. Then, $1000 \mathrm{ml}$ of flocculated sample was placed in a measuring glass and allowed to settle for $30 \mathrm{~min}$, after which the volume of the sludge was measured. The turbidity of the supernatant was measured with a Hach Ratio XR turbidimeter (model 43900; USA) and its chemical oxygen demand (COD) was measured using standardized Hach test tubes and a Hach Lange DR 2800 spectrophotometer (USA). 


\section{Sludge settling during centrifugation}

During centrifugation, an analytical centrifuge (LUMIfuge, L.U.M. GmbH; Germany) was used to evaluate the CNFCs' sludge dewatering and flocculating performance. The centrifuge consisted of a light source, a rotor above which the sample cells containing the suspension were horizontally positioned, and a Charge-Coupled Device (CCD) line sensor below the rotor. The centrifuge simultaneously measured light transmission at $800 \mathrm{~nm}$ over the plastic sample cells as a function of time and position, so local alterations in particle concentration and the position of the solid-liquid interface during separation could be detected by changes in light transmission [30]. Flocculation performance was determined from the height of the sludge cake formed, swelling of the cake and residual transmission after centrifugation at $400 \mathrm{rpm}, 3000 \mathrm{rpm}$, and then $400 \mathrm{rpm}$ again for $360 \mathrm{~s}$ at $20^{\circ} \mathrm{C}$. The flocculation performance of the suspensions was indicated by increases in the sedimentation rate and residual transmission.

\section{Results and Discussion}

\subsection{Preparation and characteristics of CNFCs}

Figure 2 shows the visual appearance of the nanocellulose samples (CNFC I at the consistency of $1 \%$ and CNFC II at the consistency of $0.5 \%$ ) and the optical transmittances for the $0.1 \%$ nanocellulose suspensions in various wavelengths. Both CNFCs were highly transparent gels, although CNFC I was more viscous than CNFC II. The optical transmittances indicated that both nanocelluloses had a high content of individual nanofibrils and a low content of unfibrillated bunches of nanofibrils, since transmittance of $80 \%$ was obtained at a wavelength of $400 \mathrm{~nm}$. 




Figure 2. Transmittance curves of CNFC I and II showing different wavelengths and visual appearances of the samples.

Figure 3 shows the charge densities (CD) of CNFC I and II in the $\mathrm{pH}$ range of from 3-10, as determinate by polyelectrolyte titration. The apparent cationic-charge density of the CNFCs decreased only slightly toward alkaline conditions, after which a sharp decrease occurred at $\mathrm{pH}$ 9. As has been noted previously, the DAC backbone is degraded rapidly by $\beta$-alkoxy fragmentation in alkaline conditions $[21,31]$ and the flocculation performance of cationic nanocelluloses decreases at alkaline $\mathrm{pH}$ values (higher than 9) [21]. Therefore, the observed degrease in apparent $\mathrm{CD}$ at $\mathrm{pH}$ values higher than 9 indicates that $\mathrm{CNFCs}$ are fragmented into smaller constituents as a result of breakage of the bond between carbon C5 and oxygen $\mathrm{O}-5$. In addition, aminoguanidine does not have a permanent charge, and thus, the charge depends on the $\mathrm{pH}$. However, in activated sludge treatments the optimum 
$\mathrm{pH}$ is closer to neutral $\mathrm{pH}$ values (6.5-7.5) than to either highly acidic or highly alkaline values, since most bacteria cannot survive at a pH higher than 9.5 or lower than 4 .

Therefore, prepared cationic nanocellulose flocculants can be assumed to work properly in conditions of activated sludge conditioning. At neutral $\mathrm{pH}$ conditions ( $\mathrm{pH} 7$ ), the charge density of CNFC I was 1.07 meq g $^{-1}$ and CNFC II 1.70 meq g $^{-1}$.

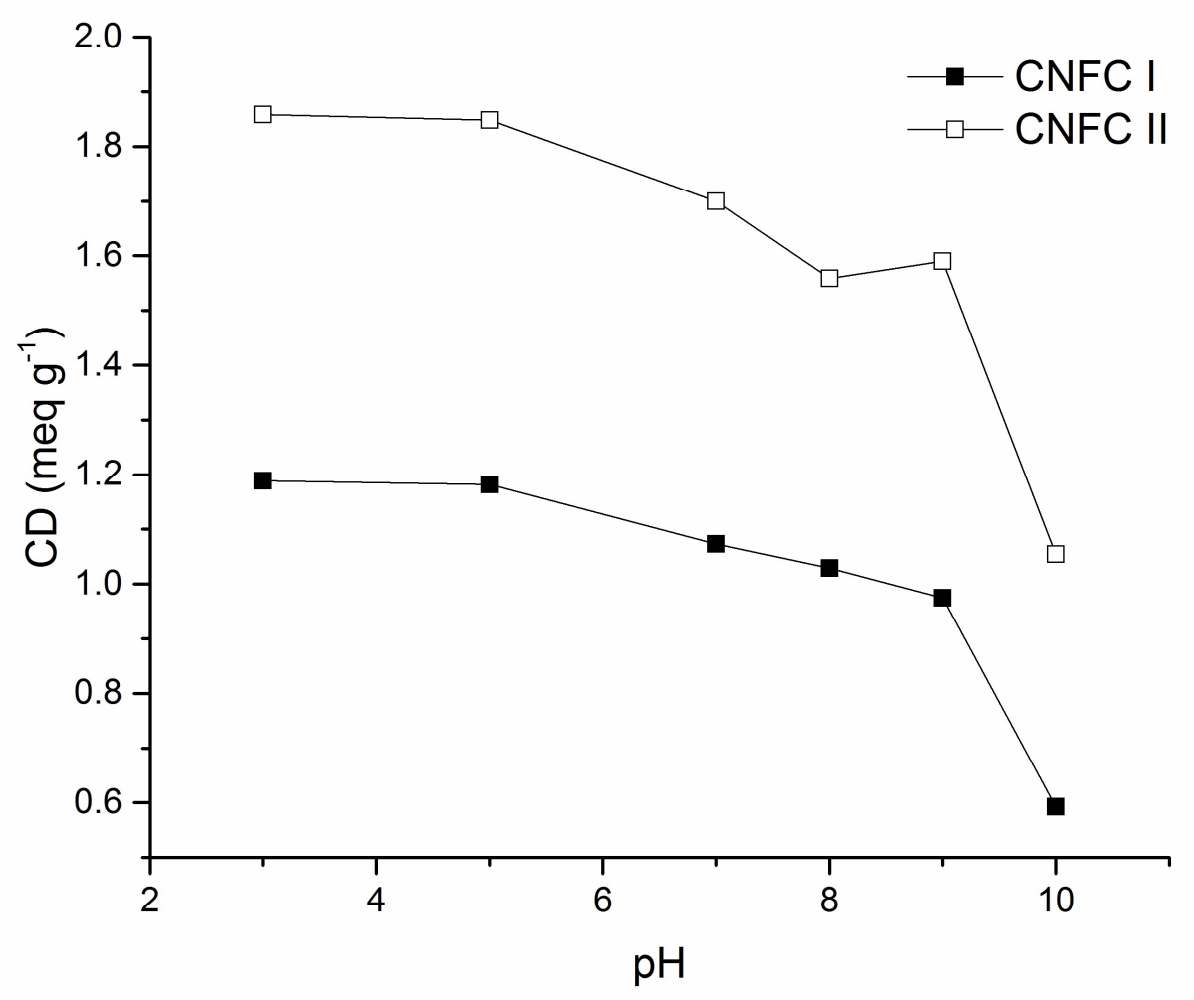

Figure 3. Charge density of CNFC I and II at various $\mathrm{pH}$ values.

Visualization of the CNFCs with TEM (Fig. 4) supported the results of optical transmittance measurement. Cellulose nanofibrils were well separated and their width was in nano-scale (6-8 nm). TEM images also showed that CNFC I had a more elongated, fibrillar shape (with widths of $2-5 \mathrm{~nm}$ and lengths of several hundred $\mathrm{nm}$ ) than CNFC II, which had a more crystalline appearance and widths of $2-8 \mathrm{~nm}$ but lengths of only $50-100$ $\mathrm{nm}$. Depending on the reaction time and conditions of periodate oxidation and further 
reactions, the product may consist of individual nanofibrils, or crystals, or a mixture of the two [32-37]. In the present study, the periodate oxidation was conducted at a higher temperature for CNFC II than for CNFC I, which may explain the more-viscous visual appearance of CNFC I (Fig. 2) and the more-crystalline structure of CNFC II (Fig. 4).


Figure 4. TEM images of produced cationic nanocelluloses, CNFC I (left) and II (right). White dots in images come from polylysine in the sample treatment.

\subsection{Flocculation experiments}

Because of its simplicity, sludge volume index (SVI) is the most common parameter used to quantify the settling (solids separation) of activated sludge. SVI has no basis in solidliquid separation theory [38,39], but a smaller SVI has found to correlate with better sludge-settling performance. In an efficiently performing activated WWTP, the SVI value is about $100 \mathrm{ml} \mathrm{g}^{-1}$. Activated sludge with an SVI of less than $120 \mathrm{ml} \mathrm{g}^{-1}$ is considered satisfactory, and an SVI of more than $150 \mathrm{ml} \mathrm{g}^{-1}$ is considered poor and caused by a high content of filament bacteria or bulking of sludge [40-42]. In the present study (Fig. 5), measured SVIs were mainly below $120 \mathrm{ml} \mathrm{g}^{-1}$, indicating satisfactory settling of the sludge. Adding low doses of the ferric coagulant and the reference synthetic polymer decreased the SVI. In addition, CNFCs decreased the SVI of sludge I, but less than did the reference synthetic polymer. Adding nanocelluloses to sludge II increased its SVI. However, increasing the dose of CNFCs decreased the SVI. Wen et al. (2015) observed this negative 
effect on SVI values in their experiment with $\mathrm{Al}^{3+}$ additions. However, they noted that adding the same amount of flocculant by means of multiple doses began to decrease the SVI [43]. They believed that the cause of the higher SVI values with low doses was that the reaction time needed to properly form sludge floc was too slow with single doses [43]. With slow mixing or multiple doses, the SVI would probably decrease with CNFCs also, due to longer contact between the nanocelluloses and the sludge material. The SVI of the more-fibrillar CNFC I decreased from $120 \mathrm{ml} \mathrm{g}^{-1}$ to $84 \mathrm{ml} \mathrm{g}^{-1}$, and the SVI of the morecationic CNFC II decreased from $120 \mathrm{ml} \mathrm{g}^{-1}$ to $88 \mathrm{ml} \mathrm{g}^{-1}$ with sludge I (Fig. 5). Therefore, CNFC I worked slightly better to decrease the SVI, although it requited higher doses.
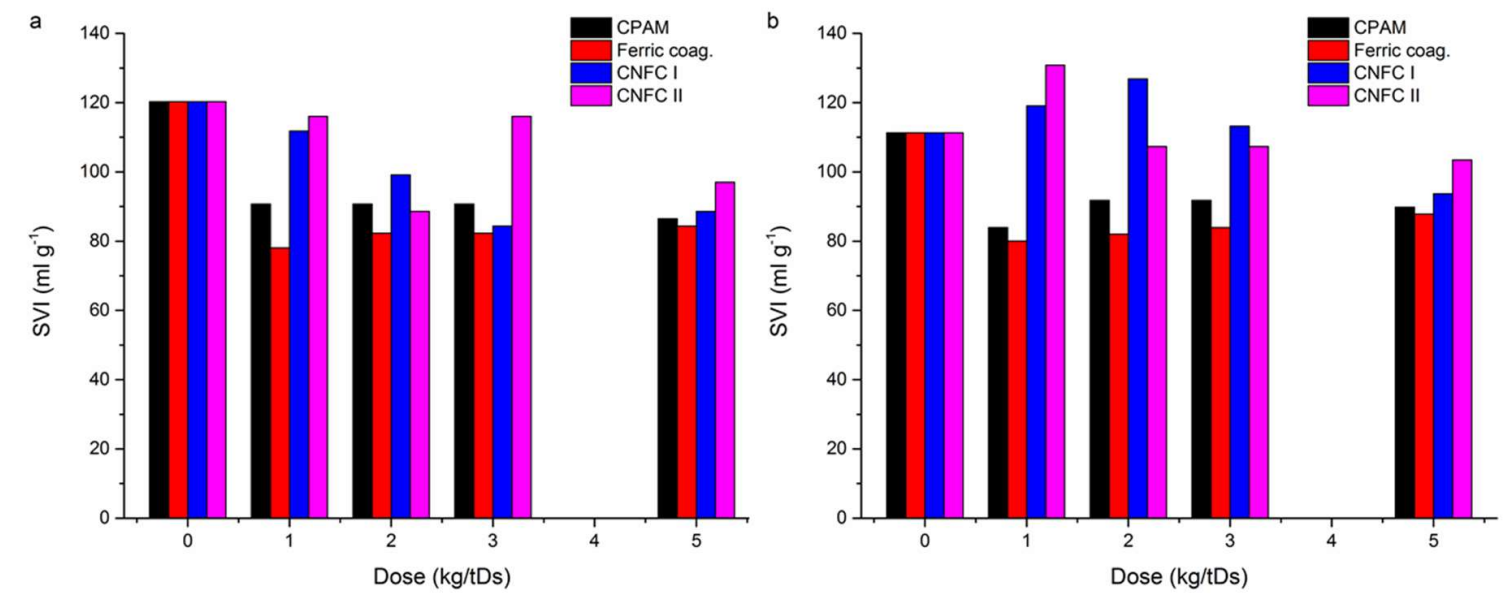

Figure 5. SVIs of the reference coagulant, flocculant and CNFCs for a) sludge I and b) sludge II. Dose: kilograms/tons of dry matter of sludge ( $\mathrm{kg} / \mathrm{tDs})$.

Both CNFCs displayed turbidity-reduction performance similar to that of the reference flocculant (Figs. 6a and c). The more-cationic CNFC II performed slightly better than did CNFC I. Both the synthetic and CNFC flocculants showed better turbidity removal than did the ferric coagulant. Both CNFCs performed better at removing COD with sludge I than did either the reference flocculant or the coagulant (Fig. 6b). With sludge II, (Fig. 6d) the reference polymer performed better at low doses than did CNFC I, but CNFC II performed similarly to the reference polymer. Since both CNFCs displayed similar purification results, the CNFC II's high cationic charge probably promoted flocculating anionic colloidal 
impurities, while CNFC I's long, flexible, nanofibril structure enhanced its flocculation performance. With higher doses, both the turbidity and COD values of the reference polyelectrolyte increased rapidly, but both remained quite constant for the CNFCs. Therefore, it seems that CNFCs are not as sensitive to overdosing as is the reference polymer. The ferric sulphate had the lowest reduction in turbidity and COD values, although increased dosing improved these results. Overall, the best purification results in terms of both turbidity and COD reduction were obtained with the CNFCs, despite the fact that their SVI values were higher than those of the commercial references. Therefore, the performance of both the CNFCs in flocculating colloidal material was as good as that of the reference polyelectrolyte or even better in the case of more cationic CNFC II.
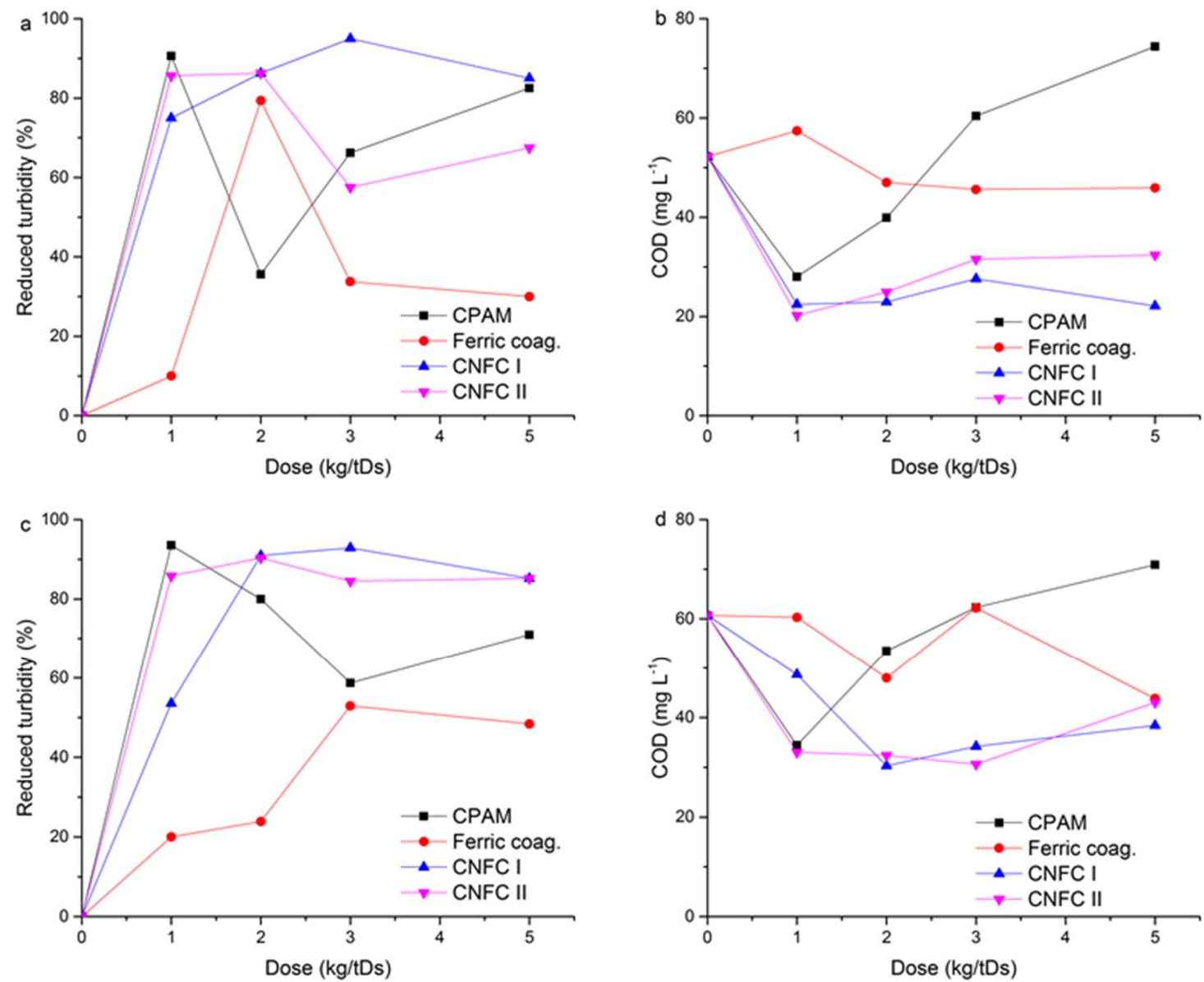

Figure 6. Reduced turbidity (a and c) and COD levels (b and d) in the supernatant of settled sludge samples. Sludge I ( $a$ and $b$ ) and sludge II (c and d). Dose: kilograms/tons of dry matter of sludge $(\mathrm{kg} / \mathrm{tDs})$. 
The present study also examined dewatering and flocculation performance of the CNFCs with a LUMI Fuge analyzer during centrifugal settling (Fig. 7). Transmittance of flocculated sludge samples was measured from the middle of the cuvette after 2 minutes of centrifugation at $400 \mathrm{rpm}$ (marker lines in Fig. 7). Centrifugation was continued for 2 minutes more at $3000 \mathrm{rpm}$, and the height of the sludge cakes was measured (colored columns in Fig. 7). Then, the samples were centrifuged for 2 minutes more at $400 \mathrm{rpm}$, and the height of the sludge cakes were measured again (gray columns in Fig. 7). The last height of the cakes indicates how much they swelled by absorbing more water after centrifugation at a slower rotational velocity. The reference polymer notably increased the volume of sludge and formed the highest sludge cakes, which also had the highest swelling capacity. The transmittance of settled suspensions was increased for sludge I by the reference polymer at low dosages, but then it began to decrease, probably as a consequence of overdosing. Both CNFCs increased the volume of sludge only slightly, meaning that the heights of the cakes were close to the heights of the untreated sludge. In addition, the swelling of the cakes was moderate compared to that of the untreated sample. Both CNFCs slightly increased the turbidity of the centrifuged supernatant, and CNFC II, with its higher cationic charge, gave slightly better results than the more-fibrillary CNFC I. The ferric sulphate formed the thinnest sludge cakes with lower swelling properties, and it also had the lowest transmittance, indicating that colloidal impurities remained in the water phase.

The principle in conditioning activated sludge is to get the solid content of the sludge as high as possible, so that sludge handling is cost effective, while also getting highly purified water [44]. The reference polyelectrolyte formed a sponge-like floc structure that showed the highest swelling properties in the centrifugal experiments. Therefore, the flocs took water back to the sludge when the centrifugal force was reduced, and with higher doses, the 
amount of colloidal material increased. The flocs formed by the CNFCs were smaller, denser, and rounder, and the swelling of their cakes was moderate, so the amount of water absorbed was low, and the amount of colloidal material remained at a good level, even with higher doses.


Figure 7. Transmittance (lines) of supernatant after $400 \mathrm{rpm}$, the height of the sludge cake after $2000 \mathrm{rpm}$ and swelling of the cakes (gray columns) after $400 \mathrm{rpm}$ of centrifugation a) sludge I and b) sludge II. Dose: kilograms/tons of dry matter of sludge (kg/tDs).

\section{Conclusions}

Cationic nanocelluloses were efficiently prepared using a two-step reaction with periodate and aminoguanidine in combination with nanofibrillation with a microfluidizer. The charge densities of the nanofibrils formed were $1.07 \mathrm{meq} \mathrm{g}^{-1}$ for CNFC I and $1.7 \mathrm{meq} \mathrm{g}^{-1}$ for

CNFC II. Both nanocelluloses formed transparent solutions (transmittance $\sim 90 \%$ at 800 nm for both samples), but CNFC II exhibited a more-crystalline structure than CNFC I.

Both CNFC I and II flocculated the activated sludge efficiently at effective doses similar to those of the commercial cationic polyelectrolyte, which was used as a reference flocculant, and at doses lower than those needed for the reference commercial coagulant. The efficiency of the flocculants' turbidity reduction was nearly as good as that of the synthetic reference polymer, and their efficiency at removing COD was even better. The performance of the more-cationic CNFC II was slightly better than that of the more-fibrillar CNFC I. In 
centrifugation analyses, both CNFCs produced compact sludge cakes with moderate

swelling and with good colloidal-removal efficiency. Therefore, both CNFCs are suggested as promising, sustainable candidates in activated sludge dewatering aid.

\section{Acknowledgments}

Juha Sahi and Emilia Kaitala are recognized for their contributions to the experiments. The authors would also like to acknowledge the Measurement, Monitoring, and Environmental Efficiency Assessment (MMEA) research program of the CLEEN Ltd. Cluster for Energy and Environment.

\section{References}

[1] Recycling Portal.EU, New study on European municipal wastewater treatment plants, http://www.recyclingportal.eu/artikel/31656.shtml. (2014).

[2] Milieu Ltd, WRc, RPA, Environmental, economic and social impacts of the use of sewage sludge on land, Milieu Ltd., Brussel, Belgium, 2010. http://ec.europa.eu/environment/waste/sludge/pdf/part_iii_report.pdf_ (accessed September 7, 2014).

[3] Y. Wei, R.T. Van Houten, A.R. Borger, D.H. Eikelboom, Y. Fan, Minimization of excess sludge production for biological wastewater treatment, Water Res. 37 (2003) 4453-4467. doi:10.1016/S0043-1354(03)00441-X.

[4] M. Niu, W. Zhang, D. Wang, Y. Chen, R. Chen, Correlation of physicochemical properties and sludge dewaterability under chemical conditioning using inorganic $\begin{array}{lllll}\text { coagulants, } & \text { Bioresour. } & \text { Technol. } & 144 & \text { (2013) }\end{array}$ doi:10.1016/j.biortech.2013.06.126.

[5] B. Peeters, R. Dewil, J.F. Van Impe, L. Vernimmen, W. Meeusen, I.Y. Smets, Polyelectrolyte Flocculation of Waste Activated Sludge in Decanter Centrifuge Applications: Lab Evaluation by a Centrifugal Compaction Test, Environ. Eng. Sci. 28 (2011) 765-773. doi:10.1089/ees.2010.0377.

[6] V. Agridiotis, C.F. Forster, C. Carliell-Marquet, Addition of Al and Fe salts during treatment of paper mill effluents to improve activated sludge settlement characteristics, Bioresour. Technol. 98 (2007) 2926-2934. doi:10.1016/j.biortech.2006.10.004.

[7] H. Li, Y. Wen, A. Cao, J. Huang, Q. Zhou, The influence of multivalent cations on the flocculation of activated sludge with different sludge retention times, Water Res. 55 (2014) 225-232. doi:10.1016/j.watres.2014.02.014.

[8] Y. Luo, Z. Yang, Z. Xu, L. Zhou, G. Zeng, J. Huang, Y. Xiao, L. Wang, Effect of trace amounts of polyacrylamide (PAM) on long-term performance of activated sludge, J. Hazard. Mater. 189 (2011) 69-75. doi:10.1016/j.jhazmat.2011.01.115.

[9] T.P. Nguyen, N. Hilal, N.P. Hankins, J.T. Novak, Determination of the effect of cations and cationic polyelectrolytes on the characteristics and final properties of synthetic and activated sludge, Desalination. 222 (2008) 307-317. doi:10.1016/j.desal.2007.01.161. 
[10] T.P. Nguyen, N. Hilal, N.P. Hankins, J.T. Novak, Characterization of synthetic and activated sludge and conditioning with cationic polyelectrolytes, Desalination. 227 (2008) 103-110. doi:10.1016/j.desal.2007.07.016.

[11] G. Di Bella, M.G. Giustra, G. Freni, Optimisation of coagulation/flocculation for pretreatment of high strength and saline wastewater: Performance analysis with different coagulant doses, Chem. Eng. J. 254 (2014) 283-292.

[12] Y.C. Ho, I. Norli, A.F.M. Alkarkhi, N. Morad, Characterization of biopolymeric flocculant (pectin) and organic synthetic flocculant (PAM): A comparative study on treatment and optimization in kaolin suspension, Bioresour. Technol. 101 (2010) 11661174. doi:10.1016/j.biortech.2009.09.064.

[13] C. Rudén, Acrylamide and cancer risk - expert risk assessments and the public debate, Food Chem. Toxicol. 42 (2004) 335-349. doi:10.1016/j.fct.2003.10.017.

[14] B. Bolto, J. Gregory, Organic polyelectrolytes in water treatment, Water Res. 41 (2007) 2301-2324. doi:10.1016/j.watres.2007.03.012.

[15] W. Xing, W. Guo, H.-H. Ngo, P. Cullum, A. Listowski, Integration of Inorganic Micronutrients and Natural Starch Based Cationic Flocculant in Primary Treated Sewage Effluent (PTSE) Treatment, Sep. Sci. Technol. 45 (2010) 619-625. doi:10.1080/01496390903566739.

[16] Y. Song, J. Zhang, W. Gan, J. Zhou, L. Zhang, Flocculation Properties and Antimicrobial Activities of Quaternized Celluloses Synthesized in $\mathrm{NaOH} / \mathrm{Urea}$ Aqueous Solution, Ind. Eng. Chem. Res. 49 (2010) 1242-1246. doi:10.1021/ie9015057.

[17] C.S. Lee, J. Robinson, M.F. Chong, A review on application of flocculants in wastewater treatment, Process Saf. Environ. Prot. 92 (2014) 489-508. doi:10.1016/j.psep.2014.04.010.

[18] D. Klemm, B. Heublein, H.-P. Fink, A. Bohn, Cellulose: Fascinating Biopolymer and Sustainable Raw Material, Angew. Chem. Int. Ed. 44 (2005) 3358-3393. doi:10.1002/anie.200460587.

[19] H. Liimatainen, T. Suopajärvi, J. Sirviö, O. Hormi, J. Niinimäki, Fabrication of cationic cellulosic nanofibrils through aqueous quaternization pretreatment and their use in colloid aggregation, Carbohydr. Polym. 103 (2014) 187-192. doi:10.1016/j.carbpol.2013.12.042.

[20] H. Liimatainen, J. Sirviö, O. Sundman, O. Hormi, J. Niinimäki, Use of nanoparticular and soluble anionic celluloses in coagulation-flocculation treatment of kaolin suspension, Water Res. 46 (2012) 2159-2166. doi:10.1016/j.watres.2012.01.035.

[21] H. Liimatainen, J. Sirviö, O. Sundman, M. Visanko, O. Hormi, J. Niinimäki, Flocculation performance of a cationic biopolymer derived from a cellulosic source in mild aqueous solution, Bioresour. Technol. 102 (2011) 9626-9632. doi:10.1016/j.biortech.2011.07.099.

[22] J. Sirviö, A. Honka, H. Liimatainen, J. Niinimäki, O. Hormi, Synthesis of highly cationic water-soluble cellulose derivative and its potential as novel biopolymeric flocculation agent, Carbohydr. Polym. $86 \quad$ (2011) 266-270. doi:10.1016/j.carbpol.2011.04.046.

[23] T. Suopajärvi, H. Liimatainen, M. Karjalainen, H. Upola, J. Niinimäki, Lead adsorption with sulfonated wheat pulp nanocelluloses, J. Water Process Eng. 5 (2015) 136-142. doi:10.1016/j.jwpe.2014.06.003.

[24] T. Suopajärvi, E. Koivuranta, H. Liimatainen, J. Niinimäki, Flocculation of municipal wastewaters with anionic nanocelluloses: Influence of nanocellulose characteristics on floc morphology and strength, J. Environ. Chem. Eng. 2 (2014) 2005-2012. doi:10.1016/j.jece.2014.08.023. 
[25] T. Suopajärvi, H. Liimatainen, O. Hormi, J. Niinimäki, Coagulation-flocculation treatment of municipal wastewater based on anionized nanocelluloses, Chem. Eng. J. 231 (2013) 59-67. doi:10.1016/j.cej.2013.07.010.

[26] A.D. Dwivedi, S.P. Dubey, M. Sillanpää, H. Liimatainen, T. Suopajärvi, J. Niinimäki, Y.-N. Kwon, C. Lee, Distinctive green recovery of silver species from modified cellulose: Mechanism and spectroscopic studies, Int. J. Biol. Macromol. 76 (2015) 109118. doi:10.1016/j.ijbiomac.2015.02.032.

[27] S. Hokkanen, E. Repo, T. Suopajärvi, H. Liimatainen, J. Niinimaa, M. Sillanpää, Adsorption of $\mathrm{Ni}(\mathrm{II}), \mathrm{Cu}(\mathrm{II})$ and $\mathrm{Cd}(\mathrm{II})$ from aqueous solutions by amino modified nanostructured microfibrillated cellulose, Cellulose. 21 (2014) 1471-1487. doi:10.1007/s10570-014-0240-4.

[28] J. Sirvio, U. Hyvakko, H. Liimatainen, J. Niinimaki, O. Hormi, Periodate oxidation of cellulose at elevated temperatures using metal salts as cellulose activators, Carbohydr. Polym. 83 (2011) 1293-1297. doi:10.1016/j.carbpol.2010.09.036.

[29] J.A. Sirviö, A.-K. Anttila, A.M. Pirttilä, H. Liimatainen, I. Kilpeläinen, J. Niinimäki, O. Hormi, Cationic wood cellulose films with high strength and bacterial anti-adhesive properties, Cellulose. 21 (2014) 3573-3583. doi:10.1007/s10570-014-0351-y.

[30] A. von Homeyer, D.-O. Krentz, W.-M. Kuliche, D. Lerche, Optimization of the polyelectrolyte dosage for dewatering sewage sludge suspensions by means of a new centrifugation analyser with an optoelectronic sensor, Colloid Polym. Sci. 277 (1999) 637-645.

[31] P. Calvini, G. Conio, M. Lorenzoni, E. Pedemonte, Viscometric determination of dialdehyde content in periodate oxycellulose. Part I. Methodology, Cellulose. 11 (2004) 99-107.

[32] F. Azzam, M. Galliot, J.-L. Putaux, L. Heux, B. Jean, Surface peeling of cellulose nanocrystals resulting from periodate oxidation and reductive amination with watersoluble polymers, Cellulose. 22 (2015) 3701-3714. doi:10.1007/s10570-015-0785-x.

[33] L. Jin, W. Li, Q. Xu, Q. Sun, Amino-functionalized nanocrystalline cellulose as an adsorbent for anionic dyes, Cellulose. 22 (2015) 2443-2456. doi:10.1007/s10570-0150649-4.

[34] J.A. Sirviö, M. Visanko, O. Laitinen, A. Ämmälä, H. Liimatainen, Amino-modified cellulose nanocrystals with adjustable hydrophobicity from combined regioselective oxidation and reductive amination, Carbohydr. Polym. 136 (2016) 581-587. doi:10.1016/j.carbpol.2015.09.089.

[35] J.A. Sirviö, T. Hasa, J. Ahola, H. Liimatainen, J. Niinimäki, O. Hormi, Phosphonated nanocelluloses from sequential oxidative-reductive treatment-Physicochemical characteristics and thermal properties, Carbohydr. Polym. 133 (2015) 524-532. doi:10.1016/j.carbpol.2015.06.090.

[36] M. Visanko, H. Liimatainen, J.A. Sirviö, J.P. Heiskanen, J. Niinimäki, O. Hormi, Amphiphilic Cellulose Nanocrystals from Acid-Free Oxidative Treatment: Physicochemical Characteristics and Use as an Oil-Water Stabilizer, Biomacromolecules. 15 (2014) 2769-2775. doi:10.1021/bm500628g.

[37] H. Yang, M.N. Alam, T.G.M. van de Ven, Highly charged nanocrystalline cellulose and dicarboxylated cellulose from periodate and chlorite oxidized cellulose fibers, Cellulose. 20 (2013) 1865-1875. doi:10.1007/s10570-013-9966-7.

[38] C.M. Bye, P.L. Dold, Sludge volume index settleability measures: effect of solids characteristics and test parameters, Water Environ. Res. 70 (1998) 87-93.

[39] B. Jin, B.-M. Wilén, P. Lant, A comprehensive insight into floc characteristics and their impact on compressibility and settleability of activated sludge, Chem. Eng. J. 95 (2003) 221-234. doi:10.1016/S1385-8947(03)00108-6. 
[40] X. Meng, D. Liu, K. Yang, X. Song, G. Zhang, J. Yu, J. Zhang, Y. Tang, K. Li, A full scale anaerobic-anoxic-aerobic process coupled with low-dose ozonation for performance improvement, Bioresour. Technol. $146 \quad$ (2013) 240-246. doi:10.1016/j.biortech.2013.07.045.

[41] D.P. Mesquita, A.L. Amaral, E.C. Ferreira, Identifying different types of bulking in an activated sludge system through quantitative image analysis, Chemosphere. 85 (2011) 643-652. doi:10.1016/j.chemosphere.2011.07.012.

[42] J. Guo, Y. Peng, S. Wang, X. Yang, Z. Yuan, Filamentous and non-filamentous bulking of activated sludge encountered under nutrients limitation or deficiency conditions, Chem. Eng. J. 255 (2014) 453-461. doi:10.1016/j.cej.2014.06.075.

[43] Y. Wen, W. Zheng, Y. Yang, A. Cao, Q. Zhou, Influence of Al3+ addition on the flocculation and sedimentation of activated sludge: Comparison of single and multiple dosing patterns, Water Res. 75 (2015) 201-209. doi:10.1016/j.watres.2015.02.053.

[44] T.P. Nguyen, N. Hilal, N.P. Hankins, J.T. Novak, The relationship between cation ions and polysaccharide on the floc formation of synthetic and activated sludge, Desalination. 227 (2008) 94-102. doi:10.1016/j.desal.2007.05.038. 